\title{
Overview of Research Relevant to Modern Energy System
}

\author{
Qiang CAI ${ }^{1,2}$ \\ ${ }^{1}$ Macro Economy and Finance Research Center, Sichuan Radio and TV University; \\ ${ }^{2}$ School of Management and Economics of UESTC
}

Keywords: Modern energy system, sustainable development, renewable energy, environmental protection

\begin{abstract}
It is a significant topic of the development of Chinese macro economy in medium and long term to build high-efficiency modern energy system and balance the relation between ecological environmental protection and development of economic society. Based on the theory of sustainable development, the domestic and foreign researches involving energy, environment and economic growth are collected in the three aspects of environment \& energy safety, energy development (economic growth) \& environmental protection and energy substitution (renewable energy) \& energy forecast. The main characters and defects of existing research findings are summarized and the outlook of future further researches is given.
\end{abstract}

\section{Introduction}

The development of modern economic society relies on more and more energy supply. The development and utilization of modern social energy is still the main source of discharge of ecological and environmental pollutants. It is an important factor that influences the quality of regional environment and people's health. With more and more attention paid to ecological environment, development of green energy has become the common intention of all countries of the world in their energy strategy adjustment and has become important content of international social political and economic game. Under the background, it becomes one of energy development strategies of countries and governments to build modern energy system. The challenge it brings to different fields becomes the increasingly cutting-edge research direction in academic circles of energy, management, economy, ecology, environment and finance.

Construction of modern energy system is a developing and dynamic systematical project. It needs the integrated innovation of technology, planning optimization, policy and development mode. Considering its essence and core features, modern energy system is a completely new system based on the diversified energy structure of the combination of renewable energy sources and gas energy. It is different from traditional energy system. Its fundamental mission is to correctly cope with the complex dialectical relationship among the nature, humans and society at different layers and from different angles in the guidance of idea of sustainable development and to constantly seek the "optimal solution" of the "choice of dilemma" between energy development (or economic growth) and environmental protection. Therefore, we focus on, collate and summarize the existing researches on the mutual relation among energy, environment and economic growth.

\section{Environment and Energy Safety}

\section{Environmental Safety}

Environmental safety is a new field that environment field and safety field intersect. It is a new subject that develops in the latest years. The definition of environmental safety given by academic circles is not uniform yet. Although the scholars with different academic background of natural science and humanistic \& social science have different understanding and annotation on “environment” and “safety”, Security: A New Framework for Analysis of Barry Buzan (2003), Study on Environmental Safety and its Research Scope of Shi Jianrong (2002), Ecological Environment Safety of China of Liu Yingjie (2004) and Study on the Issue of Environmental Safety of Cai 
Shouqiu (2001) expound the issue of environmental safety from different angles and in different degrees. The researches show that the issue of environmental safety is serious in our country and has the trend of further intensification. It shall be urgently solved and broken through.

\section{Energy Safety}

In the 1970s, the theory of energy safety was put forward by some scholars when the first oil crisis happened. During the subsequent 40 years, the theory of energy safety constantly developed and changed and was constantly enriched. Some representative research achievements were got by Brook Barrington (1997), Lu Zhongwei (2003), Song Jiekun (2008), Shi Dan (2003), Wei Yiming (2006) etc. The researches show that Chinese situation of energy safety is very serious from now to 2030 and it is urgently needed to constantly adjust and improve energy strategy.

\section{Environment and Energy Safety}

In the latest ten years, many domestic and foreign scholars research the combination of energy and environment. Up to now, the representative achievements are: Environment, Society and Violence of Thomas Homer Dixon (1999), World Politics in Long Cycle of George Modelski (1987), Research on Energy and Environmental Safety Strategy of Xiu Guangli (2008), Study on the Relationship between Economic Security and Environmental Security in China of Pei Xiaofei (2008), Progress of Research on Energy and Environment of Yan Jianhua (2008), China's Environmental Policy, Energy Policy and Great Development of Western Region of Zhang Kunmin (2000). At present, ecological footprint method and analytic hierarchy process are frequently used. Representative achievements are Evaluating Chinese Efficiency of Energy Ecological Footprint of Willian Ree (1996), Lenzen Murray (2001) and Zou Yanfen (2009), The Analytic Hierarchy Process of Zhao Huancheng (1987), Application of Analytic Hierarchy Process in Assessment on Environmental Performance of Peng Ting and Jiang Peihua (2007) etc. By decreasing the influence of subjective factors, Analytic Hierarchy Process makes analysis and evaluation objective and scientific. It is especially applicable to the case that it is difficult to accurately evaluate decisions. After being improved, the method has become a practical and mature analysis tool.

With increasingly rigorous safety situation of environment and energy, there are more and more researches on relevant evaluation systems and indexes. Tao Ran (2012) summarized the current domestic and foreign construction of energy forecast models and energy safety evaluation systems and proposed that importance should be attached to the research on the system of urban energy safety evaluation indexes; based on the model of DPSIR (dynamic-pressure-status-influence-response), Lu Zhengnan (2013) built an evaluation index system for the development of low-carbon cities and took 13 cities of Jiangsu for examples to overall evaluate the current development of low-carbon economy and put forward countermeasures and suggestions for development of low-carbon cities of Jiangsu; Sun Liwen (2017) applied DPSIR model to evaluate and research the green industry transformation of Hebei; based on DPSIR model, Zhou Zhengda (2014) built an evaluation index system for the ecological effect of national large coal power base; Hu Jianbo (2016) built 9 indexes in three aspects of pressure, status and response to evaluate the energy safety of China and the result indicated that energy safety of our country rose generally from 2001 to 2012; based on the model of pressure-status-response, Liu Ruoyu (2015) built an ecological city evaluation index system that contains 3 grades and 15 concrete indexes; Meng Ming (2017) summarized the researches on new energy and micro grid.

\section{Environmental Protection, Energy Substitution (Renewable Energy) and Economic Growth}

Common environmental policy tools include pollution tax, waste-discharge standards, emission trading, R\&D subsidy, subsidy to production of renewable energy, energy tax etc. Pollution tax, waste-discharge standards, emission trading and energy tax are the measures of post-management; R\&D subsidy and subsidy to production of renewable energy are the measures of prior-management. Different policy of environmental protection imposes different influence on economic entity. In the opinion of Peretto (2008), government could use different types of tax to finance for pollution 
abatement. By expanding the growth model of Schou (2000), he respectively researched the influence of income tax and pollution tax on energy intensity and economic growth, finding that different financing mode had different influence on economic growth. Jensen (2002) introduced environmental factor into endogenous growth model to get the conclusion "policy of environmental protection goes against economic growth"; the root cause was that he focused on hindsight effect of environmental protection management of government, namely the limit of policy of environmental protection to pollution of enterprises, without considering the influence of advance investment to environmental protection when enterprises chose industry. Jensen (2002) used the dynamic common balance model of Schou (2000) to analyze the influence of advance policy of environmental protection and post-environment management tools. Smulders and Gradus (1996) think that environment is an important factor that maintains ecological safety, economic growth and sustainable development of the society. It can not only influence production function but also influence utility function of representative families. EliaSSon and Turnovsky (2003) surveyed the influence of environment policy on economic growth in the case of environmental pollution and surveyed the influence of pollution tax, emission trading and direct regulation on capital accumulation.

Above literatures relevant to the endogenous growth of environmental pollution assume that discharge of pollutants follows the investment of production factors (capital) (or the produced accessary products). In the real society, however, some problems of environmental pollution come from the use of non-renewable resources. Olli and Salo (2001) researched the historical route of using energy and thought that humans' use of energy had the dynamic evolution process: renewable energy sources - non-renewable energy sources-renewable energy sources. Grimaud and Rouge (2005) stated that the research on energy system and economic growth should not only focus on non-renewable energy resources like petroleum and coal but involve solar energy, biomass energy, hydro energy, electric energy and other new and clean renewable energy sources. Simone (2009) and Nguyen (2010) divided energy to be renewable energy and non-renewable energy, introduced production function, analyzed the dynamic process of economy in the model of endogenous growth and got balanced growth route of economic entity and existence of saddle point in stable status by strict mathematical derivation. Nguyen and Van (2010) thought that economic entity could achieve sustainable development on the optimal route if a social planner in the economic entity reasonably arranged the consumption ratio between renewable energy and non-renewable energy. However, negative externality produced from energy consumption was not considered in their model, such as environmental pollution. ISoard and Soria (2001) thought that cheap regular energy technology (mainly based on mineral fuel) competed with emerging capital-intensive renewable energy technology in electricity market. The empirical research on solar power generation and wind power generation finds that "learn in practice" is an important driving force of innovation diffusion. The progress of renewable energy technology will raise economic growth rate and improve structure of market.

The research findings indicate that the only route of achieving sustainable growth of economy is to increase investment in renewable energy while using non-renewable energy, build compensation mechanism and improve structure of energy consumption and consumption curve. The "regeneration" processing to energy in above models has great significance for maintaining social welfare and achieving the sustainable growth of economy.

In domestic researches, Yu Bo (2006) built endogenous growth model that involved exhaustion of energy and resources, limit of environmental threshold and cost of environmental improvement and studied the necessary conditions of sustainable development, namely the dynamic relation among speed of energy consumption, proportion of investment in pollution control and economic growth. The conclusion was that the premise of guaranteeing long-term stable growth of economy was to develop the substitute products of fossil energy. Zhang Bin and Zuo Hui (2007) built an endogenous growth model restrained by both energy and environment and discussed the functions of investment in environmental protection to environmental protection and economic growth. Peng Shuijun (2007) expanded the four-sector growth model based on horizontal innovation and studied 
the relation between economic growth and population increase, resource exhaustion \& technical progress. Shao Shuai (2009) introduced a labor-intensive natural resource exploitation sector passively accepting technological spillovers into growth model; he thought that resource development had crowding-out effect on technical innovation. Yang Honglin (2004) built a growth model containing renewable energy. In certain parameter conditions, mathematical derivation was used to get the explicit solution of consumption path of economic system. Tao Lei (2008) thought that technical progress should not be only emphasized for sustainable growth and the reasonable utilization of renewable resources was an effective approach for achieving sustainable growth. Hou Yong (2008) put forward three suggestions: The first is to use administrative and fiscal means to guide national economy system to sustainably invest in renewable energy in optimal dynamic investment strategy, guarantee that substitution proportion of renewable energy rises stably and slow down environmental degradation and discharge of greenhouse gases. The second is to maintain the proper high price of fossil energy for the benefit and stable development of the industry of alternative energy sources. The third is to give financial support to the industry of alternative energy sources, such as the decrease of tax charge.

\section{Energy Forecast}

Energy forecast and early warning is an emerging subject in the field of energy system science that develops in the latest year. At present, domestic relevant researches are still in their initial stage. After the energy crisis in 1973, people began realizing the importance of energy issue. The current situation and future development trend of energy attracted attention of all countries of the world. People put forward a series of models and methods which were used to research long and medium-term energy demand, including input-output model, MEDEE, LEAP, elastic coefficient of energy, time series etc.

American economist Leontief (1936) firstly put forward input-output model. HARRY C. Willting used input-output model to research the variation trend of Dutch energy intensity during 1969-1989. Luo Xianglong used input-output model to systematically analyze the production structure of a large petrochemical enterprise; indexes of products were used to forecast the demanded quantity of materials and energy.

MEDEE model is based on sector analysis method. It is an energy technology model developed by IEPE (the Institute of Energy Policy and Economics) in France in the 1980s. It was built on the basis of a series of assumptions of social economy, population and technology in certain period. Energy demand of sectors can be forecast by simulating the change of energy demand. Bruno Lapillonne used the model to forecast the energy demand of America during 1985-2000. Fu Yuequan (1994) used the model to forecast the medium and long-term energy demand of Jiangxi.

LEAP model combines sector analysis method and material object input-output method. It is a static energy economy and environment model developed by Stockholm Environmental Research Institute (SEI) in Sweden. Ranjan Kumar Bose and Chi Chunjie (2004) respectively forecast energy demand.

The method of energy consumption elastic coefficient is based on mathematical statistics. According to average growth rate per annum of GDP in future period, the change law of elastic coefficient of energy in historical stage was selected to forecast the demanded quantity of energy in future period. Liu Yanmin used elastic coefficient method to forecast supply and demand of petroleum during “the $10^{\text {th }}$ Five-Year Plan" and subsequent 10 years. Chen Juncai used elastic coefficient method, time series method and sector analysis method to forecast the energy demand of Guangdong in 2010. Time series model contains certainty analysis method and randomness analysis method. The forecast precision of pure certainty analysis method is not high and rarely used. Randomness analysis method can be divided to be stationary random analysis and non-stationary random analysis. In view of the complex nonlinearity and uncertainty of energy system, many scholars begin researching the nonlinearity and uncertainty of energy system in the latest years. Nonlinearity method is introduced to forecast energy demand. Common methods are chaotic time 
series method, artificial neural network method, genetic algorithm, grey theory etc. These methods can make up the defect of linearity method when forecasting complex energy demand.

\section{Conclusion}

In summary, the researches involving energy, environment and economic relations in modern energy system are done to be related to the following questions: The first is how to use environment policy to solve the pollution problem caused by energy consumption; the second is how to break through the restraint and growth limit of energy by improving energy-saving technique and developing renewable energy; the third is how to forecast and assess energy demand, environmental and ecological effect and carbon discharge and guarantee the safety of environment and energy. It is an arduous task to understand the action mechanism of energy system to the nature, humans and the society. Most existing literatures reflect the influence of resource exhaustion, environment management and energy substitution on economic growth and social welfare from certain angle. Actually, they are influenced by many channels; different research objects have different internal mechanisms and the final trend.

Up to now, a complete theoretical system has not formed in the researches relevant to resource exhaustion, environment management, energy substitution and economic growth in modern energy system. Especially, the researches relevant to renewable energy involve the influence of policies of government and other safety restraints (such as environmental safety and energy safety) existing in development of new energy. Most of them are qualitative descriptions and they need to be further expanded.

\section{Acknowledgement}

Fund program: National Natural Science Foundation of China "Research on the Formation Mechanism of Electricity Pricing Mechanism of Renewable Energy Sources” (71473031); Sichuan key program of basic research for application "Research on Electricity Pricing Formation Mechanism in Diversified Energy Structure” (2017 JY0200).

\section{References}

[1] Energy Research Institute of National Development and Reform Commission. Anthology of Researches on Energy Issue, 2009-2010 [M]. Beijing: Petroleum Industry Press, 2012.

[2] Energy Research Institute of National Development and Reform Commission. Anthology of Researches on Energy Issue [M]. Beijing: China Environmental Press, 2009.

[3] Energy Research Institute of National Development and Reform Commission. Anthology of Researches on Energy Issue [M]. Beijing: Petroleum Industry Press, November 2013.

[4] Wang Gehua. Energy and Sustainable Development [M]. Beijing: Chemical Industry Press, 2005.

[5] Wang Gehua. Overview of New Energy [M]. Beijing: Chemical Industry Press, 2006.

[6] Zhang Zhengmin. Research on the Economic Incentive Policy for Chinese Wind Power Generation [M]. Beijing: China Environmental Press, 2003.

[7] Cassedy E S, (translated by) Duan Lei and Huang Yongmei. Prospects for Sustainable Energy [M] Beijing: Tsinghua University Press, 2002.

[8] Wang Jinnan. Energy and Environment: China 2020 [M]. Beijing: China Environmental Press, 2004.

[9] Barry Buzan (translated by Zhu Ning). Security: A New Framework for Analysis [M]. Zhejiang: Zhejiang People’s Publishing House, 2003. 
[10] Shi Jianrong. Study on "Environmental Safety" and it's Research Scope [J]. Essays compilation for 2002 academic conference of Chinese Society for Environmental Sciences, 2002.

[11] Liu Yingjie. The Safety of Ecological Environment in China [M]. Anhui: Anhui Education Press, 2004.

[12] Cai Shouqiu. Study on the Issue of Environmental Safety [J]. Journal of Safety and Environment, 2001, 1(5): 28-32.

[13] Shi Dan. Analysis on Influence Factors of Chinese Energy Demand [D]. Wuhan: Huazhong University of Science and Technology, 2003.

[14]J.sweeney E.K.KlaverS, “Sustaining Energy Efficiency for a' Greener'World , “ Hart Energy , Vol.12 . No.3 (2007), pp.85 106.

[15]P. DaSgupta. G. Heal, "The Optimal Depletion of Exhaustible ReSources," Review of economic Studies(Symposium on the Economics of Exhaustible Resources ), Vol.41 ( 1974 ), pp.328.

[16] J.C.Pezzey C.A.Withagen ,“The RiSe , Fall and sustainability of Capital-ReSource Economies , “Scandinavian Journal of Economics , Vol.100 , No.2 ( 1998 ), pp.513 527.

[17] Zhao Yongqiang. Analysis on Indicator System of Energy Externality Evaluation [J]. Energy of China, 2010, 32 (4): 32-36.

[18] Yu Bo, Li Yongliang, Chi Chunjie. Endogenous Model of Economic Sustainable Growth Considering Energy Exhaustion and Pollution Abatement [J]. Journal of Management Sciences In China, 2006, (4).

[19] Zhang Bin, Zuo Hui. Sustainable Use of Energy, Environment Improvement and Endogenous Economic Growth [J]. China Population Resources and Environment, 2007, (5).

[20] Peng Shuijun. Natural Resource Depletion and Sustainable Economic Growth Based on a Four-Sector Endogenous Growth Model [J]. Journal of Industrial Engineering and Engineering Management, 2007, (4).

[21] S.Iniyan , L.suganthi A.S.Analld, "Energy ModelS for Commercial Energy , Energy Prediction and Substitution of Renewable Energysources , “ Energy Policy , Vol.34 , No.7 ( 2006 ), pp.2640- 2653.

[22] R. HauSman, R. Rigobon, “Analternative Interpretation of the'Resource Curse' : Theory and Policy Implications , “http :// www.nber.org / paperS / w9424.pdf , 2010.03 .08.

[23] D.V.GiuSeppe , “Natural Resources Dynamics : Exhaustible and Renewable ReSources , and the Rate of Technica lsubstitution , “ Resources PoliCy , Vol.31 , No.9 ( 2006 ), pp.172 182.

[24] D.V.Giu Seppe , "Renewable ResourceS and Waste Recycling , “ Environmental Modeling and Assessment ,Vol.9 , No.3 ( 2005 ), pp.159 167.

[25] Shao Shuai. Technological Innovation and Economic Growth in Resource-Oriented Regions: an Alternative Interpretation of "Resource Curse" Phenomenon [J]. Journal of Industrial Engineering and Engineering Management, 2009, (2).

[26] Yang Honglin, Tian Lixin, Ding Zhanwen. Sustainable Economic Growth under Restraint of Energy [J]. Systems Engineering, 2004, (4) .

[27] Tao Lei, Liu Chaoming, Chen Yan. Endogenous Growth Model under Regenerative Resources Condition [J]. Journal of Zhongnan University of Economics and Law, 2008, (1).

[28] Hou Yong, Xu Fuyuan, Cheng Wei. A Microeconomic Model of Optimized Investment Project on the Substitution of Renewable Energy [J]. Commercial Research, 2008, (5). 
[29] Li Zhixue, Liu Wei. Environmental Effects of Oil and Gas Development and its Related Management Policy [J]. Journal of China University of Petroleum (Edition of Social Science), 2009, 25(5):21-25.

[30] Li Lei, Yan Gang, Yang Jintian. The Environmental Restrictions of Energy Development in China [J]. Energy Environmental Protection, 2007, 21(4): 1-5.

[31] Wang Jian, Lu Zhengnan. A Research on Optimal Path of Renewable Energy Price with Maximum Social Welfare [J]. Industrial Engineering Journal, 2012, 15(1): 71-75.

[32] Zhao Zijian, Zhao Xu. Research on Sharing Mechanism of Renewable Power Feed-in Price [J]. Science and Technology Management Research, 2012, 32(23): 193-195.

[33] Li Chunjie, Cheng Yancong. The Welfare Effects of Electric Efficiency and Renewable Energy Subsidies [J]. Journal of North China Electric Power University, 2011(6): 14-16.

[34] Zhao Yongqiang, Xiong Nijuan. China's Economic Incentive Policies on Renewable Energy: Review and Suggestions [J]. Research on Economics and Management, 2010(4): 5-11.

[35] Tao Ran, Cai Yunze, Lou Zhenfei, Liu Weixing. Comprehensive Research of Domestic and Foreign Energy Forecast Model and Energy Safety Appraisal Systems [J]. Shanghai Energy Conservation, 2012 (1):16-21.

[36] Zhu Xia, Lu Zhengnan. Evaluation on the Low-carbon City Development based on DPSIR Model_—The Case of Jiangsu Province [J]. Technoeconomics \& Management Research, 2013 (1):115-118.

[37] Zhou Zhengda, Wang Chenxing, Fu Xiao, Quan Yuan, Wei Dong. Evaluation Index System on Ecological Effect of National Large-Scale Coal-Fired Power Base Based on the DPSIR Conceptual Model [J]. Acta Ecologica Sinica, 2014, 34 (11):2830-2836.

[38] Hu Jianbo, Wu Hangjian, Hu Xiao. Construction of Chinese Energy Safety Evaluation Index System Based on PSR Model [J]. Statistics and Decision, 2016 (8):62-64.

[39] Liu Ruoyu. Study on the Construction of Eco-City Evaluation Index System Based on PSR Model [J]. Energy Environmental Protection, 2015, 29 (5):61-64.

[40] Meng Ming, Chen Shichao, Zhao Shujun, Li Zhenwei, Lu Yuzhou. Overview on Research of Renewable Energy Microgrid [J]. Modern Electric Power, 2017, 34 (1) :1-7.

[41] Cao Yushu, You Zhuoya. Environmental Protection, Energy Substitution and Economic Growth: A Review of theory Studies in and Abroad [J]. Economic Theory and Business Management, 2010, V (6): 30-35.

[42] Cao Yushu, You Zhuoya. Resources Constraint, Energy Substitution and Sustainable Development: A Review on Abroad References of Growth Theory [J]. Journal of Zhejiang University (Humanities and Social Sciences), 2010, 40 (4): 5-13.

[43] Sun Liwen, Cao Lu, Lv Jingwei. A Study of Evaluation of Industrial Green Transformation Based on DPSIR Model: A Case Study of Hebei Province [J]. Review of Economy and Management, 2017 (4):120-127.

[44] Yan Jianhua. Progress of Research on Energy and Environment [M]. Zhejiang: Zhejiang University Press, 2008.

[45] Xiu Guangli. Research on the Strategy of Energy and Environmental Safety [M]. Beijing: China Modern Economics Publishing House, 2008.

[46] Wang Gehua. Energy and Sustainable Development [M]. Beijing: Chemical Industry Press, 2005. 
[47] Wang Gehua. Overview of New Energy [M]. Beijing: Chemical Industry Press, 2006.

[48] CaiQiang. Study on Electricity Price Formation Mechanism Based on the Renewable Energy Power Generation with the Externalities of Grid Connection, ICEMCT2015, June 13-14, 2015, Tianjin.

[49] CaiQiang, GaoYuanPan. Subsidy Policy Assessment of Renewable Energy Grid-connected Externalities, IWIEM2015, August 15-16, 2015, Gangzhou, China.

[50] CaiQiang, HuangJin. The Research on externality Evaluation Methods for the Power Generation \& Grid Connection of Renewable Energy Source. EMSE2015, August 23-24, 2015, Phuket, Thailand.

[51] CaiQiang, DuYang. Influence Analysis of Existing Financial and Tax Policies on Chinese Wind Power, AMES2016, May 27 29, 2016, Wuhan, China.

[52] Kraft J, Kraft A. On the Relationship between Energy and GNP [J]. Energy Development, 1978, (3):401-403.

[53] Lenzen Murray. A modified ecological footprint method and its application to Australia [J]. Ecological Economics, 2001, 37(2):229-255.

[54] Mario Ragwitz \& Claus Huber \& Gustav Resch. Promotion of Renewable Energy Sources: Effects on Innovation [J]. International Journal of Public Policy, 2007, 2(1): 32-56.

[55]Butler, Neuhoff. Comparision of Feed-in Tariff, Quota and Auction Mechanisms to Support Wind Power Development [J]. Renewable Energy, 2008, 33: 1854-1867.

[56] Couture T, Cory K, Kreycik C, Williams E. Policymaker's Guide to Feed-in Tariff Policy

Design[M]. National Renewable Energy Laboratory, U.S. Dept. of Energy, 2010.

[57]J.Sweeney E.K.Klavers , "Sustaining Energy Efficiency for a 'Greener'World , “ Hart Energy , Vol.12,No.3 ( 2007 ), pp.85- 106.

[58]P. Schou Polluting Nonrenewable Resources and Growth [J] Environmental and Resource

Economics, 2000, 16(2).

[59]P. Peretto. Energy Taxes and Endogenous Technological Change [J]. Journal of Environmental

Economics and Management, 2008, 45 (4).

[60]H. Jensen. Energy T axes, Voluntary Agreements and Investment Subsidies, A Micro Panel Analysis of the Effect on Danish Industrial Companies' Energy Demand [J]. Resource and Energy Economics, 2002, 24 (2).

[61]T. Olli, S.Salo. Economic Growth and T ransitions between Renewable and Nonrenewable Energy Resources [J] .European Economic Review, 2001, 45 (8).

[62]A. Grimaud, L. Rouge. Polluting Nonrenewable Resources, Innovation and Growth: Welfare and Environmental Policy [J]. Resource and Energy Economics, 2005, 27 (4).

[63]M. H. Nguyen, P. N. Van. Growth and Convergence in a Model with Renewable and Nonrenewable Resources [EB/OL]. http: // www2. Toulouse. Inra. fr/ lerna/ travaux/ cahiers, 201003- 06

[64]B. Simone, R. M. Pulselli, F. M. Pulselli. Models of Withdrawing Renewable and Nonrenewable Resources Based on Odums Energy Systems Theory and Dalys Quasi Sustainability Principle [J]. Ecological Modelng, 2009, 22 (6).

[65] T. Azomahou, B. Raouf, N. Phu. Promoting Clean Technologies: The Energy M arket 
Structure

Crucially Matters [EB/ OL]. http: // ideas. Repec.org/ p/ dgr/ unumer/ 2008032. html, 2010.03. 06.

[66] V. Simone. Sustainable Development, Renewable Resources and Technological Progress [J].

Environmental and Resource Economics, 2005, 30 (3).

[67]D. V. Giuseppe. Natural Resources Dynamics: Exhaustible and Renewable Resources, and the Rate of Technical Substitution [J]. Resources Policy, 2006, 31 (9).

[68] Lenzen Murray. A modified ecological footprint method and its application to Australia [J].

[Ecological Economics, 2001, 37(2):229-255.

[69]Willian Ree. Revisiting carrying capacity: area based indictors of sustainability [M]. In: Wackernagel M, Ecological Footprint of Nation, 1996. 